\title{
HLA-A and breast cancer in West Peninsular Malaysia.
}

\begin{abstract}
Breast cancer is the most common malignancy among females in Malaysia. Attempts have been made to investigate the association between breast cancer and human leukocyte antigen (HLA) types. However, data from those previous studies are highly variable. The aim of this study is to investigate the association between HLA-A types and clinicopathological factors in breast cancer. The frequencies of HLA-A type in 59 female patients with infiltrating ductal of the breast were determined by polymerase chain reaction method. HLA-A2/A30 and A2/A31 haplotype $(5.1 \% ; \mathrm{P}=0.045)$ as well as HLA-A30 $(5.1 \%, \mathrm{P}=0.045)$ and $\mathrm{A} 31(6.8 \%$; $\mathrm{P}=0.020)$ allele were significant higher in the patients than controls $(0 \%)$. HLA-A24 allele was negatively related to lymph node metastasis $(\mathrm{r}=-0.316 ; \mathrm{P}=0.021)$ whereas, A26 $(\mathrm{r}=$ $-0.430 ; \mathrm{P}=0.001)$ and $\mathrm{A} 36(\mathrm{r}=-0.430 ; \mathrm{P}=0.001)$ alleles were negatively correlated to distant metastasis in breast cancer. Negative correlations between HLA-A26/A36 $(\mathrm{r}=-0.430$; $\mathrm{P}=0.001), \mathrm{A} 2 / \mathrm{A} 11(\mathrm{r}=-0.276 ; \mathrm{P}=0.044), \mathrm{A} 24 / \mathrm{A} 34(\mathrm{r}=-0.430 ; \mathrm{P}=0.001)$ haplotypes and distant metastasis were identified. Interestingly, Her2 expression in breast carcinoma was negatively correlated to A11/24 haplotypes $(\mathrm{r}=-0.294 ; \mathrm{P}=0.034)$ but positively correlated to homozygous HLA-A24 $(\mathrm{r}=0.396 ; \mathrm{P}=0.040)$. In conclusion, HLA-A2, -A30 and A31 were associated with breast cancer.
\end{abstract}

Keyword: HLA-A; Breast cancer; Metastasis; Her2; Homozygous; Heterozygous. 